\title{
FORMAÇÃO DOCENTE E PLANEJAMENTO DE SALA DE AULA
}

\author{
Sérgio Ricardo Silva MAGALHÃES ${ }^{1}$ \\ Natalia Luisa COPPOLA ${ }^{2}$
}

\begin{abstract}
Resumo: $\mathrm{O}$ presente artigo trata da formação docente e do planejamento. $\mathrm{O}$ artigo tem como problema de pesquisa: qual o papel do planejamento na formação do professor, para otimizar o processo de ensino e de aprendizagem na sala de aula? O objetivo geral é estudar sobre os significados e as formas de estruturação do planejamento docente. Como objetivos específicos: estudar sobre a formação docente e, compreender como se organiza o planejamento de sala de aula. No presente estudo foi adotada a metodologia de pesquisa bibliográfica, através de três etapas de trabalho: levantamento bibliográfico, fichamento e construção do referencial teórico. Os resultados da pesquisa apontam que a formação docente é um processo contínuo, que acontece na própria prática cotidiana do professor e na participação em diversos eventos e cursos. A abordagem da formação interativo-reflexiva pressupõe o conceito de reflexão na ação e sobre a ação do fazer docente na sala de aula, que pode ser trabalhado através do planejamento. Para a concretização do planejamento de sala de aula é importante que o professor estabeleça um marco operativo, um diagnóstico e uma programação das ações a serem realizadas, que envolve objetivos, estratégias, normas e atividades permanentes.

Palavras-chave: Formação docente. Planejamento. Sala de aula.
\end{abstract}

\section{TEACHING AND PLANNING FOR THE CLASSROOM}

\begin{abstract}
This article deals with teacher training and planning. The article is a research problem: what is the role of planning in teacher education, to improve the teaching and learning in the classroom? The overall objective is to study the significance and ways of structuring the teaching plan. Specific objectives: to study on teacher training, and understand how to organize the planning of the classroom. In the present study, we adopted the methodology of literature through three stages of work: literature, annotations and construction of the theoretical. The results of this research indicated that teacher training is an ongoing process that happens in the teacher's own daily practice and participation in various events and courses. The interactive approach to training and reflective presupposes the concept of reflection in action and the action of making teaching in the classroom, which can be worked through planning. In carrying out the planning of the classroom is important for teachers to establish an operational mark, a diagnosis and a schedule of actions to be performed, involving objectives, strategies, standards and ongoing activities.
\end{abstract}

Keywords: Teacher training. Planning. The classroom.

\section{ENSEÑANZA Y PLANIFICACIÓN PARA EL CLASE}

Resumen: En este artículo se refiere a la formación docente y la planificación. El artículo es un problema de investigación: ¿cuál es el papel de la planificación en la formación docente, para mejorar la enseñanza y el aprendizaje en el aula? El objetivo general es estudiar el significado y las formas de estructurar el plan de enseñanza. Objetivos específicos: estudio sobre la formación del profesorado, y entender la forma de organizarla planificación de la clase. En el presente estudio, hemosadoptado la metodología de la literatura a través de tres etapas de trabajo: la literatura, el libro de informes y la construcción de la teoría. Los resultados de esta investigación indican que la formación docente es un proceso continuo que ocurre en la práctica diaria propia del profesor y la participación en diversos eventos y cursos. El enfoque interactivo para la formación y la reflexión presupone el concepto de reflexión en la acción y la acción de hacer de la docencia en el aula, que puede ser trabajado a través de la planificación. Para llevar a cabo la planificación de la clase es importante para los profesores para establecer un operativo de marzo, un diagnóstico y un cronograma de acciones a realizar, con objetivos, estrategias, normas y actividades en curso.

Palabras-clave: Formación docente. Planificación. Sala de clase.

\footnotetext{
${ }^{1}$ Pós-Doutor em Educação pela Universidad de Flores (UFLO). Docente da Universidade Vale do Rio Verde (UninCor), E-mail: sergio.magalhaes@unincor.edu.br

${ }^{2}$ Doutora em Educação pela Universidad Complutense de Madrid (UCM). Docente Convidada da Universidad de Flores (UFLO). E-mail: naticop@gmail.com
} 


\section{Introdução}

O tema deste artigo é a formação docente e o planejamento. Nas últimas décadas, a sociedade passou por mudanças profundas, especialmente a educação, que precisa acompanhar todos os processos de mudanças nas sociedades. Para melhor responder aos imperativos do momento e compreender a vida em sociedade, o homem precisa, basicamente, de reflexão e planejamento. Pela reflexão, o homem desenvolve níveis cada vez mais aprimorados de discernimento, compreensão e julgamento da realidade, favorecendo a conduta inteligente em situações novas de vida. Pelo planejamento, o homem, organiza e disciplina a sua ação, partindo sempre para realizações cada vez mais complexas.

$\mathrm{Na}$ área de educação e ensino, a formação docente e o planejamento são processos importantes e muito enfatizados atualmente, tanto no interior das instituições escolares quanto na produção acadêmica. A profissão docente é uma prática educativa, ou seja, como tantas outras, é uma forma de intervir na realidade social, no caso, mediante a educação. Nesse sentido, o artigo tem como problema de pesquisa: qual o papel do planejamento na formação do professor, para otimizar o processo de ensino e de aprendizagem na sala de aula?

Foi escolhido o tema pela sua relevância teórica em repensar o planejamento dirigido para uma ação crítica e transformadora, possibilitando ao professor maior segurança para lidar com a relação educativa a sala de aula e na instituição de ensino como um todo. E, pela sua relevância social em instigar mudanças na concepção de planejamento como processo integrador, na qual professores e alunos produzam conhecimentos com possibilidades de contribuir concretamente para a transformação da sociedade.

O objetivo geral é estudar sobre os significados e as formas de estruturação do planejamento docente. E, como objetivos específicos: estudar sobre a formação docente e, compreender como se organiza o planejamento de sala de aula.

No presente estudo foi adotada a metodologia de pesquisa bibliográfica, através de material já elaborado, consistindo de livros, artigos científicos e publicações periódicas. Para responder ao problema de pesquisa e aos objetivos propostos, foram desenvolvidas três etapas de trabalho. A primeira etapa consistiu de levantamento bibliográfico. De acordo com Bogdan e Biklen (1994), a exploração da literatura sobre o tema a estudar contribui mais significativamente para o desenvolvimento do mesmo. Nesta etapa, o planejamento de estudo foi realizado através de leitura crítica de todo o material consultado e anotação dos pontos relevantes pertinentes ao tema proposto. A segunda etapa consistiu do procedimento de fichamento, através de leitura seletiva do material levantado, 
estabelecendo relações entre as informações, o problema e objetivos propostos (GIL, 2010). E, a terceira etapa consistiu da construção do referencial teórico.

O artigo está estruturado em três partes. Na primeira parte, autores como Nóvoa e Finger (2010), Freire (2010), Santos (2007), Pacheco (2006), Libâneo (2005), Fazenda (2003), Tardif (2002), Schön (1998), Gatti (1997) e Mello (1996) contextualizam a formação contínua dos professores, enfocando a interdisciplinaridade e o modelo interativoreflexivo de formação docente. Após essa abordagem, a segunda parte discorre sobre os significados e condições de estruturação do planejamento, assuntos abordados por autores como Gandin e Cruz (2010), Lima (2005), Fontana (2004), Gandin (2003; 1996), Libâneo (2002), Ferreira (2001), Padilha (2001), Vasconcellos (2000) e Coll (1997). A terceira parte aborda a questão do planejamento de sala de aula, com contribuições teóricas de Gandin e Cruz (2010).

\section{Formação docente: uma prática necessária}

Atualmente, existe uma significativa preocupação com a formação contínua de professores. Pode-se dizer, de uma maneira geral, que a formação do professor tem início antes do seu ingresso nos cursos de preparação para o magistério e prossegue durante o exercício da sua prática profissional. Os estudantes já chegam aos cursos de formação profissional com conceitos e representações sobre o papel do professor. Essas imagens e essas experiências prévias têm influência na formação do docente. Além disso, durante o exercício da profissão, o professor vai adquirindo novas competências sobre o seu ofício, provenientes da própria prática cotidiana.

Amplia-se dessa forma, a concepção de que a formação é somente uma decorrência direta dos cursos de preparação para a docência. Essa formação passa a ser vista como algo bastante complexo que depende não apenas dos conhecimentos ou das experiências sobre ensino e aprendizagem ou de como organizá-los. Mas, envolve também a filtragem desses conhecimentos e experiências a partir de valores, atitudes e disposições pessoais conferindo, a cada professor, um estilo pessoal e singular. Como dizem Nóvoa e Finger (2010),

\begin{abstract}
A formação do docente pressupõe a reelaboração ou a recriação dos saberes dados pelos cursos, feita a partir das experiências vivenciadas tanto como aluno, antes e durante o curso de formação inicial, como também posteriormente adquiridas no desempenho da atividade profissional (ibid, p. 17).
\end{abstract}

Considerando-se, então, a formação como um processo dinâmico e com possibilidade de aperfeiçoamento crescente, pode-se entender também essa formação como um processo contínuo. Nesse sentido, a prática profissional pode ser concebida como elemento constitutivo da formação continuada 
dos profissionais. No entanto, denomina-se formação continuada ou formação contínua ou formação em serviço, em sentido mais estrito, todas as formas deliberadas e organizadas de aperfeiçoamento profissional do docente. Estas formas podem acontecer através de palestras, seminários, cursos, oficinas ou outras propostas. Dessa forma, a formação contínua a que se refere aqui consiste em propostas voltadas para a qualificação do docente, tendo em vista as possibilidades de melhoria de sua prática pelo domínio de conhecimentos e de métodos de seu campo de trabalho. Esses conteúdos, trabalhados nas diferentes modalidades de educação contínua, podem estar relacionados com a superação de problemas ou de lacunas na prática docente. $\mathrm{Ou}$, ainda, promovendo a introdução de um novo repertório de conhecimentos de natureza teórica ou prática, decorrentes da produção de novos saberes nas diferentes áreas de conhecimento. Nesse sentido, torna-se importante, após as considerações feitas até aqui, analisar as características da prática docente, tentando estabelecer vínculo entre esses elementos, ou seja, entre os processos de formação contínua e a prática docente à qual eles se destinam.

É comum, na literatura pedagógica educacional, dizer que as atividades docentes pressupõem, inicialmente, conhecimentos sobre uma área ou áreas específicas denominados por Tardif (2002) de 'saberes das disciplinas'. Esses saberes são adquiridos, nos casos dos cursos de licenciatura, nos departamentos ou institutos pertencentes a instituições de ensino superior e correspondem às diferentes áreas do conhecimento como a física, a matemática, a geografia etc. O professor precisa, ainda, conhecer teorias de aprendizagem, de currículo, de metodologia, de estratégias e de recursos instrucionais para planejar seu trabalho e organizar as experiências de ensino a serem desenvolvidas em sala de aula. Estes podem ser chamados conforme Tardif (2002, p.32) de "saberes pedagógicos, pois incluem conhecimentos advindos de áreas como a psicologia, a didática e o currículo".

Além disso, têm sido muito discutidos, hoje, os chamados saberes práticos ou saberes da experiência, que dizem respeito àqueles conhecimentos e habilidades que $\mathrm{o}$ professor vai adquirindo com o exercício de sua atividade. É um saber que é adquirido no fazer, podendo ser caracterizado como um conhecimento tácito que leva as pessoas a darem respostas a situações da vida profissional de forma quase automática, sem conseguirem, muitas vezes, explicar este saber/fazer. Isso acontece quando professores experientes já não conseguem explicar como conseguem, por exemplo, captar a atenção de uma sala ou acalmar um grupo agitado.

Esses saberes, segundo Tardif (2002), podem incluir dois grupos de competências. No primeiro grupo estariam as competências organizacionais ou relacionais. No segundo grupo, estariam os saberes relativos aos conhecimentos das normas e 
valores presentes na cultura da instituição escolar. Também, o conhecimento das características do grupo de alunos de sua turma, o que fornece ao professor critérios e princípios com os quais ele reelabora os saberes da disciplina e os saberes pedagógicos. Pode-se dizer que esse tipo de conhecimento, do segundo grupo, oferece, então, as condições para que o professor recontextualize ou retraduza diferentes saberes, de acordo com a realidade do contexto onde atua. $\mathrm{O}$ que ocorre rotineiramente no preparo de planejamentos, atividades e exercícios relacionados ao ensino e à avaliação. Nesse sentido, de acordo com Tardif (2002), a experiência provoca um feedback ao professor para que ele possa filtrar, selecionar e retomar os saberes necessários à sua prática docente.

A formação contínua pode partir tanto de iniciativas pessoais quanto institucionais, podendo ambas ser individuais ou coletivas. Como exemplo de iniciativa pessoal, tem-se o caso do ingresso em cursos de especialização, escolhidos pelo próprio professor, realizados em horário diferente do seu horário de trabalho e de sua responsabilidade exclusiva. Como exemplo da iniciativa de caráter coletivo, grupos de professores pagam a um profissional para lhes dar uma assessoria técnica e psicopedagógica, com o objetivo de ajudá-los a resolver seus problemas de sala de aula. As iniciativas institucionais podem também ser individuais ou coletivas. $\mathrm{Na}$ forma individual, a instituição promove a qualificação de seus professores, liberando-os total, ou parcialmente, de suas funções e/ou arcando com o pagamento das despesas para a realização, dentre outros, de estágios técnicocientíficos, cursos de especialização e pósgraduação/mestrado ou doutorado. A forma coletiva, mais usual, é aquela realizada através de cursos, seminários, oficinas de formação, semanas de estudos etc., oferecidos aos professores pelo sistema de ensino ou pelas escolas (ou consórcio de escolas). A participação nessas atividades pode ser tanto voluntária como compulsória.

Muitos dos objetivos dos processos de formação contínua já foram mencionados. Destacam-se, dentre outros, aqueles relacionados aos conteúdos, aos métodos de ensino e ao planejamento de sala de aula, cuja necessidade advém de lacunas na formação inicial ou em decorrência da necessidade de atualização. Os objetivos de capacitação podem estar ainda, ligados aos problemas da prática docente ou às relações entre professor e aluno.

Uma forma por meio do qual esse processo de formação contínua pode ser conduzido é através do modelo interativoreflexivo, que toma como base o relato das histórias da vida educacional do professor. Segundo Nóvoa e Finger (2010), o método biográfico na área da educação veio a se revelar não apenas como instrumento de investigação, mas também como instrumento de formação. Essa forma de educação 
continuada comporta duas modalidades: a presencial e à distância. Hoje em dia, cresce o número das propostas de formação à distância. Nesta forma é mais comum o uso da tecnologia/Internet tendo ainda, como suporte, algum tipo de material impresso.

De acordo com Schön (1998), a literatura sobre a formação de professores destaca a necessidade da formação do professor reflexivo, capaz de refletir na ação e sobre a ação e os processos de formação que partam da análise de situação prática profissional do docente. Assim, a forma interativo-reflexiva, ou seja, as propostas de formação centradas na solução de problemas da prática são destacadas por Schön (1998), como aquela capaz de melhor preparar o docente para o enfrentamento de situações futuras, de trabalho, dos princípios, pressupostos e valores subjacentes às suas rotinas e aos seus hábitos de trabalho. Para Gatti (1997, p. 21), a formação do tipo escolar também é eficiente, quando o objetivo é apenas a divulgação de novas teorias ou propostas pedagógicas, pois "a tendência entre os docentes é valorizar a presença do professor e considerar que, sem essa presença física, qualquer processo educacional é falho e não se desenvolve plenamente". Pelo exposto até o momento pode-se perceber que as competências específicas do professor configuram um campo teórico/prático e interdisciplinar, que implica o desenvolvimento da identidade e consciência profissionais, que perpassam pela formação de docentes reflexivos.

A formação reflexiva é um dos conceitos na área educacional mais utilizado por estudiosos, formadores de professores e educadores diversos, para se referirem às novas tendências da formação de professores, onde a reflexão é colocada como um instrumento de desenvolvimento do pensamento e da ação. Schön (1998) contribui para melhor entendimento da formação docente propondo o conceito de reflexão-naação, como o processo mediante o qual os professores aprendem a partir da análise e interpretação da sua própria atividade. A importância dos estudos de Schön (1998) consiste assim, em destacar a própria prática do professor que conduz necessariamente à criação de um conhecimento específico e ligado à ação. Portanto, falar sobre a formação de professores reflexivos significa também falar sobre currículo, consciência ética de professores, dimensão pedagógica e política da formação contínua.

Com a evolução das tecnologias de comunicação e informação vão surgindo novas demandas por profissionais que possam atuar num mercado competitivo. Nesse sentido, vão também aparecendo algumas propostas educacionais que valorizam a técnica, o planejamento, o método, o desenvolvimento de certas habilidades e estratégias de maneira a assegurar, conforme Schön (1998), um bom desempenho em sala de aula. Isto, segundo o mesmo autor, a partir 
da reflexão como fonte de produção de um saber-fazer que se dá através da análise da própria prática. É possível, a partir da reflexão, questionar as técnicas, métodos e estratégias utilizadas e descobrir as teorias implícitas que fundamentam a ação do professor. Essa reflexão na ação e sobre a ação, segundo Schön (1998), torna o profissional um pesquisador que define os meios e os fins da sua ação, de forma interativa.

Um dos aspectos que influencia a formação de profissionais reflexivos está ligado à forma de ser das instituições escolares. A escola tem de ser um espaço de formação capaz de possibilitar aos seus profissionais a aquisição de novos conhecimentos a partir da discussão e análise das próprias ações educativas. A escola deve assegurar, por meio da sua organização, que a formação dos professores se dê de forma contínua, interativa e dinâmica. Por isso, Nóvoa e Finger (2010) consideram que é necessário compreender como e em que condições o conhecimento dos professores, acerca de suas práticas, vem sendo produzido nas escolas. Não basta afirmar que a formação profissional deve ocorrer concomitantemente com a prática educativa, tampouco que os profissionais devem ser reflexivos e autônomos. É preciso que se questione o modo como as práticas escolares, com seus condicionantes, podem limitar ou restringir a ação dos professores e influenciar sua formação.

\section{Buscando}

compreender

as

instituições escolares, Nóvoa e Finger (2010) ressaltam dois aspectos que as caracterizam. O primeiro deles diz respeito aos imperativos institucionais que são aqueles que estão presentes em toda e qualquer escola, seja ela privada, pública ou confessional: o saber escolar, o tempo escolar e a avaliação. O segundo aspecto é a cultura das instituições escolares: ritmos, ritos, linguagem, imaginário, modos de regulação/transgressão e regimes próprios de produção e de gestão de símbolos. A partir da interação que os profissionais da educação estabelecem com esses aspectos citados, é possível perceber os conflitos que emergem e como os professores vão se formando ou não a partir desses conflitos. Por isso, Nóvoa e Finger (2010, p.19) afirmam que "a formação docente é algo muito mais profundo e complexo do que a aquisição de habilidades, de competências". Não se trata só de um problema cognitivo, mas também dos professores refletirem sobre os valores, as definições éticas, as visões de homem, de educação e de mundo ao longo de suas vidas pessoais e profissionais.

$$
\text { Schön (1998), Tardif (2002), }
$$

Fazenda (2003), Freire (2001; 2002; 2011), Santos (2007) e Nóvoa e Finger (2010), apresentam-se alguns eixos de conhecimento e competência que os professores precisam desenvolver e mobilizar, para avançar na direção do campo da formação reflexiva. São os seguintes eixos: assumir o ensino como mediação, através da aprendizagem ativa do 
aluno, com a sua ajuda pedagógica; modificar a ideia de uma escola e de uma prática pluridisciplinares para uma escola e uma prática interdisciplinares; conhecer estratégias do ensinar a pensar e do ensinar a aprender a aprender; ajudar os alunos a buscarem uma perspectiva crítica dos conteúdos; assumir e planejar o trabalho de sala de aula como um processo comunicacional, desenvolvendo a capacidade comunicativa; considerar o impacto das novas tecnologias da comunicação e informação na sala de aula; atender à diversidade cultural e respeitar as diferenças no contexto da escola e da sala de aula; investir na atualização científica, técnica e cultural, como ingredientes do processo de formação continuada; integrar a dimensão afetiva no exercício da docência; desenvolver um comportamento ético e orientar os alunos em valores e atitudes em relação a si próprios, à vida, ao ambiente e às relações humanas.

De acordo com Santos (2007), o professor faz a mediação pedagógica do aluno com a matéria, inclusive com os conteúdos próprios de sua disciplina, mas considerando os conhecimentos, a experiência e os significados que os alunos trazem à sala de aula, seu potencial cognitivo, suas capacidades e interesses, seus procedimentos de pensar, seu modo de trabalhar. Ao mesmo tempo, o professor ajuda no questionamento dessas experiências e significados, provê condições e meios cognitivos para sua modificação por parte dos alunos e orienta-os, intencionalmente, para objetivos educativos.
É o que Schön (1998) chama de ensinar a aprender a pensar.

Muitas escolas adotam uma prática interdisciplinar, onde a noção mais conhecida é a de interação entre duas ou mais disciplinas para superar a fragmentação e a compartimentalização de conhecimentos. A característica central da interdisciplinaridade, segundo Fazenda (2003, p. 27), consiste no fato de ela conseguir incorporar os resultados de várias especialidades, "tomando-lhes de empréstimo esquemas conceituais de análise, instrumentos e técnicas metodológicas, a fim de fazê-los integrar, depois de havê-los comparado e julgado". Nessa noção está a ideia de ligar o conhecimento científico a uma cognição prática, isto é, de compreender a realidade para transformá-la.

Atitudes e práticas interdisciplinares, todavia, não são incompatíveis com a organização do currículo por disciplinas escolares, que têm por base as disciplinas científicas, porque não há prática interdisciplinar sem a especialização disciplinar. O vício principal do currículo por disciplinas, de acordo com Fazenda (2003), é reduzir o ensino à exposição oral dos conteúdos e ao material informativo do livro didático, sem considerar $\mathrm{o}$ processo de investigação, os modos de pensar a que as disciplinas recorrem e a funcionalidade desses conteúdos para a análise de problemas e situações concretas da vida prática cotidiana. Para Fazenda (2003), uma mudança de atitude dos professores diante $\mathrm{da}$ rigidez $\mathrm{da}$ 
organização disciplinar implica compreender a prática da interdisciplinaridade em três sentidos: como atitude, como forma de organização administrativa e pedagógica da escola e, como prática curricular.

A interdisciplinaridade, num enfoque totalizante da realidade, cria modos e condições de ajudar os alunos a se colocarem ante a realidade para pensá-la e atuar nela, pois conforme Freire (2010), a apropriação crítica da realidade significa contextualizar um tema de estudo buscando compreender suas ligações com a prática humana. Em consonância com esta colocação, Libâneo (2005) diz que o professor, ao trabalhar determinado tema, deve perguntar a si próprio e aos alunos como, nas várias esferas da vida social, intervêm, modificam e constroem esse tema de estudo.

Não se pode ignorar também, o trabalho com as informações advindas da sociedade tecnológica. Mesmo dependendo do quadro negro (ou outro dispositivo), dos cadernos e dos livros didáticos, as tecnologias de comunicação e informação impactam na escola e na vida cotidiana e, de acordo com Pacheco (2006), professores e alunos precisam aprender a ler sons, imagens, movimentos e a lidar com eles. Em relação aos alunos, estes já vivenciam fora da escola um mundo cheio de imagens, de sons e de cores. Por isso, segundo Pacheco (2006), a escola e seus professores devem fazer esta ponte entre o mundo informacional $\mathrm{e}$ comunicacional com o conhecimento escolar, ajudando o aluno a atribuir significados à informação fragmentada e superficial, principalmente dos meios de comunicação.

Dessa forma, os recursos tecnológicos podem ajudar a problematizar e criticar as informações veiculadas pelos meios de comunicação, orientar as discussões e preencher as lacunas do que não foi apreendido em sala de aula. Isto demanda uma nova atitude do professor diante dos meios de comunicação, não apenas como recursos didáticos, mas conforme Mello (1996), também como um conjunto das mediações culturais que caracterizam o ensino. Nesse sentido, para Libâneo (2005), os meios de comunicação apresentam-se, pedagogicamente, sob três formas conjugadas: como conteúdo escolar integrante das várias disciplinas do currículo, como competências e atitudes profissionais dos professores e como meios tecnológicos de comunicação humana nos aspectos visuais, cênicos, verbais, sonoros e audiovisuais. Além da incorporação das inovações tecnológicas, o exercício do trabalho docente requer uma sólida cultura geral, um esforço contínuo de atualização científica na sua disciplina e em campos de outras áreas relacionadas.

Outro eixo importante para que os professores avancem na direção do campo da formação reflexiva, é o atendimento à diversidade cultural e ao respeito às diferenças no contexto da escola e da sala de aula. Esse respeito à diversidade e às 
diferenças implica um posicionamento de "ver em cada indivíduo a presença do universal e simultaneamente a do particular" (PACHECO, 2006). Atender à diversidade cultural implica, pois, reduzir a defasagem entre o mundo vivido do professor e o mundo vivido dos alunos, bem como promover, efetivamente, a igualdade de condições e oportunidades de escolarização a todos. Permeando estes eixos de formação reflexiva, a dimensão afetiva e a dimensão ética são importantes para uma aprendizagem significativa.

\section{Significados e condições de estruturação do planejamento}

Os significados que envolvem o planejamento são amplamente discutidos nos dias atuais. Assim sendo, procura-se explicitar os significados básicos desse termo, visando a dar espaço para o estabelecimento de relações entre eles. Um significado atribuído ao planejamento é dado por Padilha (2001) como:

Processo de reflexão, de tomada de decisão sobre a ação; processo de previsão de necessidades e racionalização de emprego de meios (materiais) e recursos (humanos) disponíveis, visando à concretização de objetivos, em prazos determinados e etapas definidas, a partir dos resultados das avaliações (ibid, p. 30).

Ainda para Padilha (2001, p.33), planejamento é o processo de decisão sobre atuação concreta dos professores, no cotidiano de seu trabalho pedagógico, “envolvendo as ações e situações, em constantes interações entre professor e alunos e entre os próprios alunos". Para Gandin (1996, p.17), o planejamento visa, além da eficiência, a eficácia das organizações. De acordo com este autor, a eficiência relacionase ao 'fazer bem o que se faz' e a eficácia ao 'fazer o que é realmente importante fazer', porque é socialmente desejável e leva, no conjunto das ações, a fins pré-estabelecidos em harmonia às crenças existentes. Gandin e Cruz (2010) compreendem o planejamento como um processo educativo, com vistas a transformar a realidade numa direção escolhida e dar clareza e precisão à própria ação. Planejar, para estes autores, é definir o que se quer alcançar, verificar a que distância, na prática, se está do ideal e decidir o que se vai fazer para encurtar essa distância. O planejamento se sustenta, então, em três objetivos: elaborar, executar e avaliar.

Em outra obra, Gandin (2003, p.44) apresenta uma noção de planejamento como ferramenta que, segundo seu fim, é facilitar ou possibilitar o trabalho de organizar a ação, ou seja, "possibilitar (ou facilitar) a inclusão, a supressão, o fortalecimento ou a diminuição de ideias na realidade ou estabelecer novas relações entre elas". Para Libâneo (2002, p.221), planejamento envolve o processo de reflexão, de decisões sobre a organização, o funcionamento e a proposta pedagógica da instituição, pois, "é um processo de racionalização, organização e coordenação da ação docente, articulando a atividade escolar e 
a problemática do contexto social". Vasconcelos (2000, p. 79) complementa que o planejamento, enquanto construção e transformação de representações, "é uma mediação teórico-metodológica para a ação que, em função de tal mediação, passa a ser consciente e intencional". Dessa forma, enquanto significado de processo e de construção, o planejamento escolar é uma dimensão fundamental do trabalho pedagógico, porque permite aos professores e à escola controlar os resultados e a consecução das finalidades desse trabalho. É por meio do planejamento, de seu desenvolvimento e de sua avaliação que a escola afirma a sua autonomia e o seu saber específico. Ao planejar, a escola controla os fins de seu trabalho, define os meios para alcançar esses fins, estabelece instrumentos para sua auto-avaliação, redefine, com base na avaliação, suas metas e meios.

Quando a escola, seus profissionais de educação e os professores abrem mão do planejamento, eles abrem mão de sua autonomia, de seu saber e do controle de seu trabalho. Abrem mão até da possibilidade de desenvolvimento de sua formação, pois é planejando e se avaliando que a escola e os docentes geram um contexto de ampliação de seu saber, pela criação da necessidade de estudo, de elaboração de novas estratégias, de análise e reflexão sobre problemas encontrados. O planejamento, desse modo, é importante instrumento por meio do qual a escola e seus profissionais asseguram $\mathrm{o}$ controle autônomo de seu trabalho. Para tanto, essa tarefa de planejar exige condições de estruturação para ser realizada.

Em seu modelo, dentro da estruturação do planejamento escolar, Gandin (1996, p.20) defende a contínua reflexão em torno de três questões centrais: "o que queremos alcançar; a que distância estamos daquilo que queremos alcançar; o que faremos concretamente (em tal prazo) para diminuir esta distância”. Ferreira (2001) apresenta três fases de um processo de planejamento participativo: (1) a preparação do plano escolar, entendido como o registro sistematizado e justificado das decisões tomadas pelos agentes educacionais que vivenciam o dia a dia da escola; (2) o acompanhamento da execução das operações pensadas no plano escolar, de forma a fazer, caso seja necessário, as alterações nas operações para o alcance dos objetivos propostos; (3) a revisão de todo o caminhar, avaliando as operações que favoreceram o alcance dos objetivos e aquelas operações que pouca influência teve sobre o mesmo, iniciando-se assim um novo planejamento. $\mathrm{O}$ planejamento caracteriza-se, desta forma, como um processo ininterrupto de planejar, acompanhar, avaliar e replanejar.

As condições para o processo de planejamento são estabelecidas de acordo com aquilo que se deseja definir, organizar e planejar. Fontana (2004) coloca que um processo de planejamento deveria se estruturar em torno de cinco grandes 
conjuntos de procedimentos: (1) criando condições para o planejamento;

estabelecendo e compartilhando as finalidades ou metas a serem alcançadas; (3) definindo os meios para alcançar essas metas ou finalidades; (4) escolhendo instrumentos de registros das atividades; (5) avaliando o que se planejou e o que se realizou.

Lima (2005) também aponta três aspectos a serem seguidos para elaboração do planejamento de ensino. O primeiro aspecto diz respeito à finalidade ou propósito educativo, que se expressa por um enunciado geral sobre as intenções educativas; são afirmações de princípios por meio das quais o grupo veicula seus valores. $\mathrm{O}$ segundo aspecto são as metas educacionais, que definem, de uma maneira geral, as intenções perseguidas por uma instituição, grupo ou indivíduo, mediante um programa ou uma ação educativa determinada. $\mathrm{O}$ terceiro aspecto são os objetivos, que "explicitam as intenções educativas e estabelecem as capacidades que os alunos poderão desenvolver como consequência de ações intencionais do professor" (ibid, p. 7).

De acordo com Coll (1997), o planejamento origina vias diferentes de acesso às intenções educativas: a via de acesso pelos conteúdos e a via de acesso pelas atividades. $\mathrm{Na}$ via de acesso pelas atividades - que é uma das características fundamentais dos currículos abertos - a idéia básica é a de que existem atividades com valor educativo intrínseco, independentemente do seu conteúdo concreto e dos possíveis aprendizados verificáveis que possam originar. Desse modo, o planejamento de ensino deve consistir em identificar as atividades com maior valor educativo intrínseco e em favorecer que os alunos participem delas.

Para Lima (2005), o ato de aprender requer investigação, averiguação, questionamento, mudança, resistência, criação, dúvida, ebulição, enfim, transgressão. “Todos esses atributos do ato de aprender estão concatenados com o ato de planejar, até porque planejamento é, acima de tudo, hipótese, parâmetro e, portanto reflexão, não rigidez" (ibid, p.8). Assim, a multiplicidade de intenções que presidem o planejamento educacional leva à questão da sua organização e sequênciação temporal e deve ser prevista uma avaliação que permita verificar se a ação pedagógica corresponde adequadamente às intenções perseguidas.

O planejamento é um poderoso instrumento para que o professor aumente suas condições de questionar o que hoje se faz na escola e, sobretudo, construa maneiras concretas de transformar a realidade escolar. A próxima seção discorre sobre a concretização do planejamento na sala de aula.

\subsection{O planejamento de sala de aula}

O planejamento de sala de aula faz parte do plano global da instituição escolar, 
que expressa o seu marco referencial e que guia o trabalho de cada professor e de cada turma de alunos. Para Gandin e Cruz (2010), o planejamento de sala de aula deve conter três elementos. $\mathrm{O}$ primeiro elemento, um marco operativo, ou seja, "um ideal, um fim a ser alcançado, uma convicção" (ibid, p. 26). O segundo elemento, um diagnóstico, isto é, "a expressão da distância que o grupo de alunos está desse ideal, com a indicação das falhas e das causas destas falhas, das dificuldades para avançar e dos pontos de apoio" (ibid, p. 26). O terceiro elemento, uma programação que é "a proposta de ações a realizar, atitudes a vivenciar, normas para seguir e rotinas para praticar" (ibid, p. 27).

O marco operativo é o referencial, a indicação do rumo que o professor pretende seguir na sua disciplina, isto é, "o projeto de contribuição da disciplina ao crescimento das pessoas e à construção de uma sociedade" (ibid, p. 29). A disciplina traz sua maneira própria de contribuir na construção social e pessoal, na perspectiva da globalidade instituída pelo grupo todo da instituição escolar. Nesse sentido, para ajudar na elaboração do marco operativo, Gandin e Cruz (2010) sugerem que o professor reflita sobre os principais aspectos de sua disciplina, seu significado no mundo atual, as habilidades, atitudes, conhecimentos a serem desenvolvidos pelos alunos, os princípios metodológicos, as estratégias mais adequadas, os temas de trabalho, as formas de avaliação, o cronograma de atividades, dentre outros. $\mathrm{O}$ diagnóstico, de acordo com Gandin e Cruz (2010), é uma avaliação contínua que pressupõe, de tempos em tempos, uma visão sobre os interesses e expectativas dos alunos, vivências pessoais e profissionais e, uma avaliação se está sendo vivenciado em sala de aula aquilo que está proposto no marco operativo.

A programação das ações envolve objetivos, estratégias, normas e atividades permanentes (GANDIN; CRUZ, 2010). Para os autores, objetivo é a expressão de uma ação concreta, a ser realizada pelo professor, pelos alunos ou, concomitantemente, por ambos, para sanar determinadas necessidades e, assim, transformar a realidade, para aproximá-la do que ficou estabelecido no marco operativo. Por isso, ao enunciar um objetivo, "deve-se dizer o que se vai fazer e para que se vai fazê-lo" (ibid, p. 71).

Para Gandin e Cruz (2010), estratégia é a expressão de uma atitude a ser vivenciada pelo professor, pelos alunos ou por ambos, para sanar determinadas necessidades e, assim, transformar a realidade, para aproximá-la do que ficou estabelecido no marco operativo. Enquanto objetivo é a expressão de uma ação concreta, a estratégia é a expressão de uma atitude.

\footnotetext{
Nesse sentido, uma estratégia é um modo de viver. Alguém pode dizer que propõe uma estratégia para sua vida quando decide que vai fazer exercícios físicos; estabelecer isso não é definir uma ação concreta fechada (como se faz no objetivo), mas é tomar uma atitude que vai ter consequências muito importantes, inclusive a de gerar ações concretas (ibid, p. 80).
} 
Essa compreensão é importante para elaboração de estratégias que podem ser retiradas tanto do plano mais abrangente da instituição escolar e do curso, e/ou especificamente construídas para a prática concreta da sala de aula. Assim, o planejamento de sala de aula de determinada disciplina, na perspectiva de Gandin e Cruz (2010), tem a seguinte estrutura: I - Marco Operativo; II - Diagnóstico; III Programação: objetivos, estratégias, normas e atividades permanentes. É necessário, então, planejar, isto é, pensar o modo e os recursos que se vai empregar na realização das ações, pensar como vão se realizar as estratégias, as normas $\mathrm{e}$ as atividades permanentes, sem esquecer a avaliação dos processos que vão sendo realizados.

\section{Considerações finais}

Este artigo, em busca de maior esclarecimento sobre a formação docente e o planejamento de sala de aula, aponta algumas considerações conclusivas. A formação docente é decorrente tanto da própria prática cotidiana do professor quanto da participação em diversos eventos e cursos. Por isso é um processo contínuo de saberes da disciplina que ministra e saberes pedagógicos.

A abordagem da formação interativo-reflexiva pressupõe o conceito de reflexão na ação e sobre a ação, aonde a própria prática do professor conduz à criação de um conhecimento específico, numa visão interdisciplinar e ligado ao seu fazer na sala de aula. Conhecimento este que exige reflexão sobre os valores, as diversidades culturais, as diferenças, as definições éticas, as visões de homem, de educação e de mundo. E, ainda, não desvinculado das demandas da sociedade e do mercado tecnológico e competitivo e que exige, planejamento, habilidades e estratégias de forma a assegurar um bom desempenho em sala de aula.

O estudo apontou também que o planejamento escolar é um processo participativo de construção, reconstrução, ressignificação e avaliação do trabalho pedagógico. O planejamento de sala de aula faz parte do plano global da instituição escolar, que expressa o seu marco referencial e que guia o trabalho de cada professor e de cada turma de alunos. Para a concretização deste planejamento é importante que o professor estabeleça um marco operativo, um diagnóstico e uma programação das ações a serem realizadas, que envolve objetivos, estratégias, normas e atividades permanentes.

Torna-se assim, importante, que a formação continuada do professor contemple a temática do planejamento de sala de aula, para melhor definição do que se quer alcançar, indicação da distância a que se está desse ideal e proposta para diminuir tal distância. 


\section{Referências}

BOGDAN, Robert; BIKLEN,

Sari. Investigação qualitativa em educação.

Porto: Porto Editora, 1994.

COLL, César. Psicologia e Currículo: uma aproximação psicopedagógica à elaboração do currículo escolar. São Paulo: Ática, 1997.

FAZENDA, Ivani Catarina Arantes.

Interdisciplinaridade: história, teoria e pesquisa. 11. ed. São Paulo: Papirus, 2003.

FERREIRA, Naura Syria Carapeto (Org). Gestão democrática da educação: atuais tendências, novos desafios. 3 ed. São Paulo: Cortez, 2001.

FONTANA, Roseli A. Cação. Mediação pedagógica na sala de aula. Campinas: Autores Associados, 2004.

FREIRE, Paulo. Pedagogia da autonomia: saberes necessários à prática educativa. 43. ed. Rio de Janeiro: Paz e Terra, 2010.

GANDIN, Danilo e CRUZ, Carlos Henrique Carrilho. Planejamento na sala de aula. 10 ed. Petrópolis, RJ: Vozes, 2010.

GANDIN, Danilo. Planejamento

Educacional. Sistema de Ação Pedagógica SIAPE/MG. Dicionário do Professor: Participação e Gestão Escolar. Belo Horizonte: SEE-MG, 2003.

GANDIN, Danilo. Planejamento como prática educativa. São Paulo: Loyola, 1996.

GATTI, Bernadete Angelina. Formação de professores e carreira: problemas e movimentos de renovação. Campinas: Autores Associados, 1997.

GIL, Antonio Carlos. Como elaborar projetos de pesquisa. 5. ed. São Paulo: Atlas, 2010.
LIBÂNEO, José Carlos. Democratização da escola pública: a pedagogia crítico-social dos conteúdos. 20. ed. São Paulo: Loyola, 2005.

LIBÂNEO, José Carlos. Organização e gestão escolar: teoria e prática. 4. ed. Goiânia: Editora alternativa, 2002. LIMA, Marilene. Planejamento de ensino. Revista do Professor. Porto Alegre: CPOEC, v. 21, n. 83, p. 07-13, jul.-set., 2005.

MELLO, Guiomar Namo de. (Org.) Escola Nova, tecnicismo e educação compensatória. São Paulo: Loyola, 1996.

NÓVOA, António; FINGER, Matthias (Org.). O método (auto)biográfico e a formação. São Paulo: Paulus, 2010.

PACHECO, José Augusto Brito. Currículo: teoria e práxis. Porto: Porto Editora, 2006.

PADILHA, Paulo Roberto. Planejamento dialógico: como construir o projeto políticopedagógico da escola. São Paulo: Cortez, 2001 .

SANTOS, Lucíola Licínio de Castro Paixão. Paradigmas que orientam a formação docente. In: SOUZA, João Valdir Alves de. (Org.). Formação de professores para a educação básica: dez anos da LDB. 1 ed. Belo Horizonte: Autêntica, 2007. p. 235-252.

SCHÖN, Donald A. Formar professores como profissionais reflexivos. In: NÓVOA, António (org.). Os professores e a sua formação. Lisboa: Nova Enciclopédia, 1998.

TARDIF, Maurice. Saberes docentes e formação profissional. 7. ed. Petrópolis, RJ: Vozes, 2002.

VASCONCELLOS, Celso dos Santos. Planejamento: projeto de ensino aprendizagem e projeto político pedagógico. São Paulo: Libertad, 2000. 